\title{
Left ventricular function in adults with mild pulmonary insufficiency late after Fallot repair
}

\author{
R A Niezen, W A Helbing, E E van der Wall, R J van der Geest, H W Vliegen, A de Roos
}

\begin{abstract}
Objective-To assess left ventricular function in adult Fallot patients with residual pulmonary regurgitation.

Setting-The radiology department of a tertiary referral centre.

Patients-14 patients with chronic pulmonary regurgitation and right ventricular volume overload after repair of tetralogy of Fallot and 10 healthy subjects were studied using magnetic resonance imaging.

Main outcome measures-Biventricular volumes, global biventricular function, and regional left ventricular function were assessed in all subjects.

Results-The amount of pulmonary regurgitation in patients (mean (SD)) was 25 (18)\% of forward flow and correlated significantly with right ventricular enlargement $(p<0.05)$. Left ventricular end diastolic volume was decreased in patients (78 (11) $\left.v 88(10) \mathrm{ml} / \mathrm{m}^{2} ; \mathrm{p}<0.05\right)$, ejection fraction was not significantly altered (59 (5)\% $v 55$ (7)\%; NS). No significant correlation was found between pulmonary regurgitation and left ventricular function. Overall left ventricular end diastolic wall thickness was significantly lower in patients (5.06 (0.72) $v 6.06(1.06) \mathrm{mm}$; p < 0.05), predominantly in the free wall. At the apical level, left ventricular systolic wall thickening was $20 \%$ higher in Fallot patients $(p<0.05)$. Left ventricular shape was normal.

Conclusions-Adult Fallot patients with mild chronic pulmonary regurgitation and subsequent right ventricular enlargement showed a normal left ventricular shape and global function. Although the left ventricular free wall had reduced wall thickness, compensatory hypercontractility of the apex may contribute to preserved global function.

(Heart 1999;82:697-703)
\end{abstract}

Keywords: left ventricular function; pulmonary insufficiency; tetralogy of Fallot; magnetic resonance imaging

Long term survival of patients after complete surgical repair of tetralogy of Fallot is reduced compared with the general population. ${ }^{1}$ A number of factors may contribute to diminished life expectancy in Fallot patients. Residual stenosis of the right ventricular outflow tract and pulmonary regurgitation are well known clinical problems after Fallot surgery. Pulmonary regurgitation is recognised for its adverse effects on pulmonary blood flow and right ventricular function. Pulmonary regurgitation is also associated with right ventricular hypertrophy, right ventricular dilatation, and the development of arrhythmias which may be related to sudden death. ${ }^{2-5}$

Several investigators have observed impaired left ventricular function at rest in patients with pulmonary regurgitation after Fallot repair, while others have found normal left ventricular function in similar patient groups. ${ }^{26-12}$ This discrepancy has not been explained.

Magnetic resonance imaging (MRI) has been successfully used to evaluate right ventricular function and pulmonary flow in postoperative Fallot patients. ${ }^{513-15}$ However, a detailed study of left ventricular function in Fallot patients with chronic pulmonary regurgitation has not been performed with MRI. Accordingly, the aim of this study was to assess left ventricular function in adult Fallot patients with long standing pulmonary regurgitation after Fallot repair in childhood.

\section{Methods}

STUDY SUBJECTS

Since 1994, MRI has been part of a standard protocol in the follow up of repaired adult Fallot patients in our institution. From 1994 to the end of 1997, consecutive patients were selected from the institutional MRI database containing 80 repaired adult Fallot patients. All patients had chronic residual pulmonary regurgitation on clinical examination. Patients with known residual shunts (intracardiac or extracardiac), tricuspid insufficiency, pulmonary stenosis with a Doppler gradient of more than $30 \mathrm{~mm}$ $\mathrm{Hg}$, systemic hypertension, or aortic valve disease were not included in the study. The observers did not have prior knowledge of other demographic, procedural, or haemodynamic data. Fourteen adult Fallot patients (mean (SD) age 30 (11) years), and 10 age matched, healthy control subjects (mean age 33 (7) years) were studied.

Patients underwent surgery at a mean age of 5 (4) years and were studied 24 (8) years postoperatively. All patients were operated upon using cardiopulmonary bypass and profound hypothermia. In three patients, surgery had been performed with a transatrialtranspulmonary approach. In 10 patients a transannular patch was used. Table 1 summarises the clinical and surgical data on the patients and the control subjects. All patients were in New York Heart Association (NYHA) functional class I, except for three patients who were in class II. All but two patients had a complete right bundle branch block configuration on the ECG, and all showed regular sinus rhythm during the MRI investigation. 
Table 1 Clinical and surgical data of patients and age matched control subjects

\begin{tabular}{lll}
\hline & $\begin{array}{l}\text { Patients } \\
(n=14)\end{array}$ & $\begin{array}{l}\text { Controls } \\
(n=10)\end{array}$ \\
\hline $\begin{array}{ll}\text { Male/female } \\
\text { Age (years) }\end{array}$ & $5 / 9$ & $4 / 6$ \\
Body surface area $\left(\mathrm{m}^{2}\right)$ & $30(11)$ & $33(7)$ \\
Palliative shunt & $1.84(0.2)$ & $1.86(0.2)$ \\
Age at surgery (years) & 3 & \\
Postoperative time (years) & $5(4)$ & \\
Transannular patch & $24(8)$ & \\
Right ventriculotomy & 10 & \\
Preoperative Hb (g\%) & 3 & \\
Preoperative oxygen saturation $(\%)$ & $13(4)$ & \\
Minimum temperature at surgery $\left({ }^{\circ} \mathrm{C}\right)$ & $25(4)$ & \\
\hline
\end{tabular}

Values are mean (SD) or $\mathrm{n}$.

$\mathrm{Hb}$, haemoglobin.

The investigation protocol was approved by the committee on medical ethics of our institution and all subjects gave informed consent.

MAGNETIC RESONANCE IMAGING

MRI studies were performed with a 1.5 Tesla system (NT15 Gyroscan, Philips Medical Systems, Best, Netherlands). Scout views were obtained in transverse, coronal, and sagittal planes using a standard, multislice spin echo sequence.

\section{Short axis gradient echo images}

A multiphase, ECG triggered, multishot echoplanar gradient echo (GRE) technique was used to acquire short axis images. The scout views were used to plan 10 to 12 short axis slices perpendicular to the long axis of the heart and covering both ventricles. GRE images were acquired during breath holds, each lasting 10 to 15 seconds. Slice thickness was $10 \mathrm{~mm}$. Echo time was shortest (5-10 ms) and the flip angle was set to $30^{\circ}$. Between 18 and 25 time frames were acquired over one cardiac cycle, resulting in a temporal resolution between 22 and $35 \mathrm{~ms}$. A field of view of 350 to $400 \mathrm{~mm}$ was used, depending on the size of the patient.

\section{Magnetic resonance flow measurements}

In the patient group, measurements of great vessel and mitral flow were obtained using a velocity encoded cine MRI sequence. A slice

ED phase

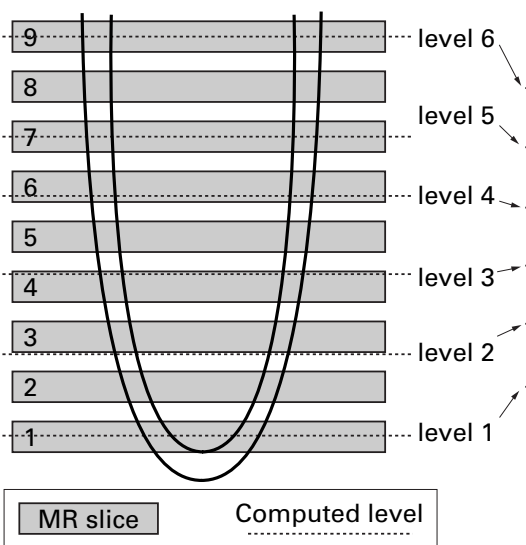

Figure 1 Schematic representation of the method used to correct for through plane motion of the ventricle. A standardised subdivision in six levels from apex to base was established, levels 1 and 6 corresponding to the most apical and basal image slice, respectively, and the other levels at evenly spaced intervals computed by linear interpolation of the corresponding two neighbouring image slices. Levels 1 and 2 were defined as apical, levels 3 and 4 as midventricular, and levels 5 and 6 as basal. ED, end diastole; ES, end systole. thickness of $8 \mathrm{~mm}$ and a field of view of $300 \times$ $300 \mathrm{~mm}$ were used. The flip angle was $20^{\circ}$ and the echo time was $12 \mathrm{~ms}$. For velocity mapping of the great vessels, a double oblique plane perpendicular to the vessel was used. The sequence was encoded for through plane velocities up to $2 \mathrm{~m} / \mathrm{s}$. Using retrospective gating, 30 to 40 time frames evenly distributed over the cardiac cycle were constructed, resulting in a temporal resolution of 25 to $35 \mathrm{~ms}$. A $128 \times 128$ scan matrix was interpolated to a display matrix of $256 \times 256$. For velocity mapping of the mitral valve, a double oblique plane was positioned perpendicular to the valvar orifice using a four chamber GRE series. The GRE images were displayed in cine mode to study movement of the mitral orifice during the cardiac cycle. The imaging plane was positioned halfway between the end diastolic and end systolic position of the mitral valve, perpendicular to the direction of flow. The sequence was encoded for through plane velocities up to $100 \mathrm{~cm} / \mathrm{s}$.

MAGNETIC RESONANCE IMAGE ANALYSIS

All images were quantitatively analysed by two experienced observers on a SUN Ultra Sparc 1 workstation (SUN Microsystems, Mountain View, California, USA) using two software packages which were developed at our institution. ${ }^{1617}$

\section{Magnetic resonance flow measurements}

Velocity maps were analysed using the FLOW analytical software package. ${ }^{17}$ This package provides semiautomated contour detection of vessel cross sections and subsequent quantification of flow volumes. On the modulus image of every time frame, contours of the aortic or pulmonary wall or mitral valve annulus were traced, edited manually, and projected on the corresponding phase images. Subsequently, instantaneous flow data were calculated and displayed as a flow curve. From these flow curves the amount of pulmonary regurgitation, and net flow volumes were calculated for the great vessels. From mitral flow curves the following indices of left ventricular diastolic function were calculated, as described before. ${ }^{13}$ Total time for image analysis per patient was one to two hours.

Ventricular volumes and mass-Using the MR Analytical Software System (MASS 3.0), ${ }^{16}$ ventricular volumes, ejection fraction, and left ventricular wall mass were determined from the short axis GRE images as described previously. ${ }^{13}{ }^{14}$ In one patient GRE images of the right ventricle were of insufficient quality because of sternal wire artefacts. Thus right ventricular volumes of 13 patients were obtained.

Left ventricular wall thickness and thickeningRegional left ventricular end diastolic and end systolic wall thickness (in $\mathrm{mm}$ ), and wall thickening (as a percentage of the end diastolic wall thickness) were assessed using a three dimensional extension to the centreline method as previously described, ${ }^{18}$ including a correction for through plane motion of the ventricle (fig 1). The ventricle was subdivided into six levels from 


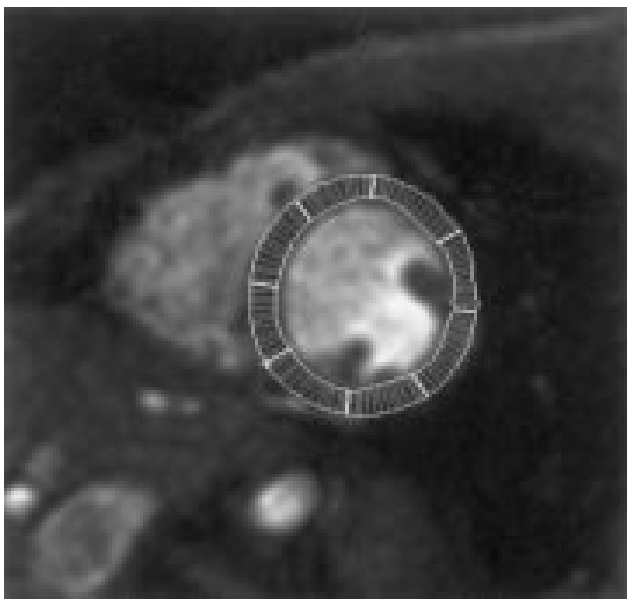

Figure 2 Example of an end diastolic midventricular short axis slice through the heart of a healthy volunteer. The centreline cords subdivide the left ventricular wall in a clockwise fashion into eight regions starting at the junction of both ventricles.

apex to base, levels 1 and 6 corresponding to the most apical and basal image slice, respectively, and the other levels at evenly spaced intervals computed by linear interpolation of the corresponding two neighbouring image slices. Levels 1 and 2 were defined as apical, levels 3 and 4 as midventricular, and levels 5 and 6 as basal. Circumferentially, the centreline chords were subdivided into eight regions in a clockwise fashion starting at the junction of the two ventricles (fig $2)$. The first three regions cover the septal wall, the subsequent five regions the lateral and inferior wall of the left ventricular. For each level and region (48 ventricular zones in total) the three dimensional wall thickness was computed for the end diastolic and end systolic phases, and wall thickening expressed as a percentage of the mean wall thickness was defined as:

$$
\frac{\mathrm{WT} \%=(\text { WTES-WTED }) \times 100 \%}{\text { WTED }}
$$

where ES is end systole and ED is end diastole. Peak rate of wall thickening and thinning - In one midventricular slice, representative of the entire left ventricle, endocardial and epicardial contours were drawn on all images obtained during one cardiac cycle. Left ventricular wall thickness curves were obtained in 12 patients and eight control subjects in this midventricular slice using the centreline method. Subsequently these curves were filtered using low pass Fourier filtering as previously described. ${ }^{19}$ Systolic wall thickening and diastolic wall thinning were assessed by determining the peak rate of wall thickening and the peak rate of wall thinning expressed in percentage of the mean wall thickness per ms. ${ }^{20}$ Peak rate of wall thickening and thinning were determined for the whole myocardial wall in this slice and for eight individual wall segments.

Left ventricular eccentricity-Possible left ventricular cavity distortion owing to a septal shift and flattening of the ventricle was assessed from the same midventricular slice by calculating ventricular eccentricity. ${ }^{21}$ The length of the short axis diameter from the left ventricular endocardium of the midventricular septum to the endo- cardium of the lateral free wall was defined as D1. The length of the orthogonal short axis diameter from the left ventricular endocardium of the inferior to the anterior free wall was defined as D2. Left ventricular eccentricity was defined as D2/D1.

STATISTICAL ANALYSIS

All measurements were corrected for heart rate and body surface area when appropriate. Left ventricular wall mass was also compared, determined on both end diastolic and end systolic time points. Stroke volumes and pulmonary regurgitation were compared by linear regression analysis. Mitral flow measurements of patients were compared with mitral flow measurements obtained in age matched control subjects with comparable heart rates. For comparison of patients with control subjects a two tailed, unpaired $t$ test was used. Values were expressed as mean (SD) when appropriate. Probability (p) values $<0.05$ were considered statistically significant.

\section{Results}

PULMONARY FLOW AND RIGHT VENTRICULAR VOLUMES

In patients, mean (SD) net pulmonary stroke flow was $39(9) \mathrm{ml} / \mathrm{m}^{2}$. The amount of pulmonary regurgitation per heart cycle in patients was $16(12) \mathrm{ml} / \mathrm{m}^{2}$ or $25(18) \%$ of right ventricular stroke volume.

Right ventricular end systolic and end diastolic volumes were greater in patients than in controls, at 64 (25) v 46 (13) $\mathrm{ml} / \mathrm{m}^{2}$ $(\mathrm{p}<0.05)$ and 119 (32) v 92 (15) $\mathrm{ml} / \mathrm{m}^{2}$ $(\mathrm{p}<0.05)$, respectively. Right ventricular stroke volume was increased in the patient group, at $55(12) v 46(5) \mathrm{ml} / \mathrm{m}^{2}(\mathrm{p}<0.05)$. Right ventricular ejection fraction was not significantly different in patients and controls (48 (8) $\%$ v $51(8) \%$ (NS)). The severity of regurgitation (in $\mathrm{ml} / \mathrm{m}^{2}$ ) correlated with right ventricular end diastolic volume $(p<0.05)$ and right ventricular stroke volume $(p<0.01)$ (fig 3 , A and B). Pulmonary regurgitation did not correlate significantly with right ventricular end systolic volume (fig 3C) or right ventricular ejection fraction (NS). The severity of regurgitation (in $\mathrm{ml} / \mathrm{m}^{2}$ ) also correlated significantly with time after operation $(\mathrm{p}<0.05)$.

MITRAL AND AORTIC FLOW

None of the mitral flow indices differed significantly between patients and controls (table 2). The mean (SD) aortic stroke flow in patients was $39(8) \mathrm{ml} / \mathrm{m}^{2}$.

\section{LEFT VENTRICULAR VOLUMES}

Left ventricular end systolic volume in patients was lower than in healthy volunteers (table 3); however, this difference was not statistically significant (32 (7) $v 39$ (9) $\mathrm{ml} / \mathrm{m}^{2}$, NS). Left ventricular end diastolic volume was smaller in patients than in healthy volunteers, at 78 (11) $v$ 88 (10) $\mathrm{ml} / \mathrm{m}^{2}(\mathrm{p}<0.05)$. Left ventricular stroke volumes and left ventricular ejection fraction did not differ significantly between patients and controls, at $44(6) v 49(6) \mathrm{ml} / \mathrm{m}^{2}$ (NS) and $59 \quad(5) \% \quad v \quad 55 \quad$ (7)\% $\quad$ (NS), 

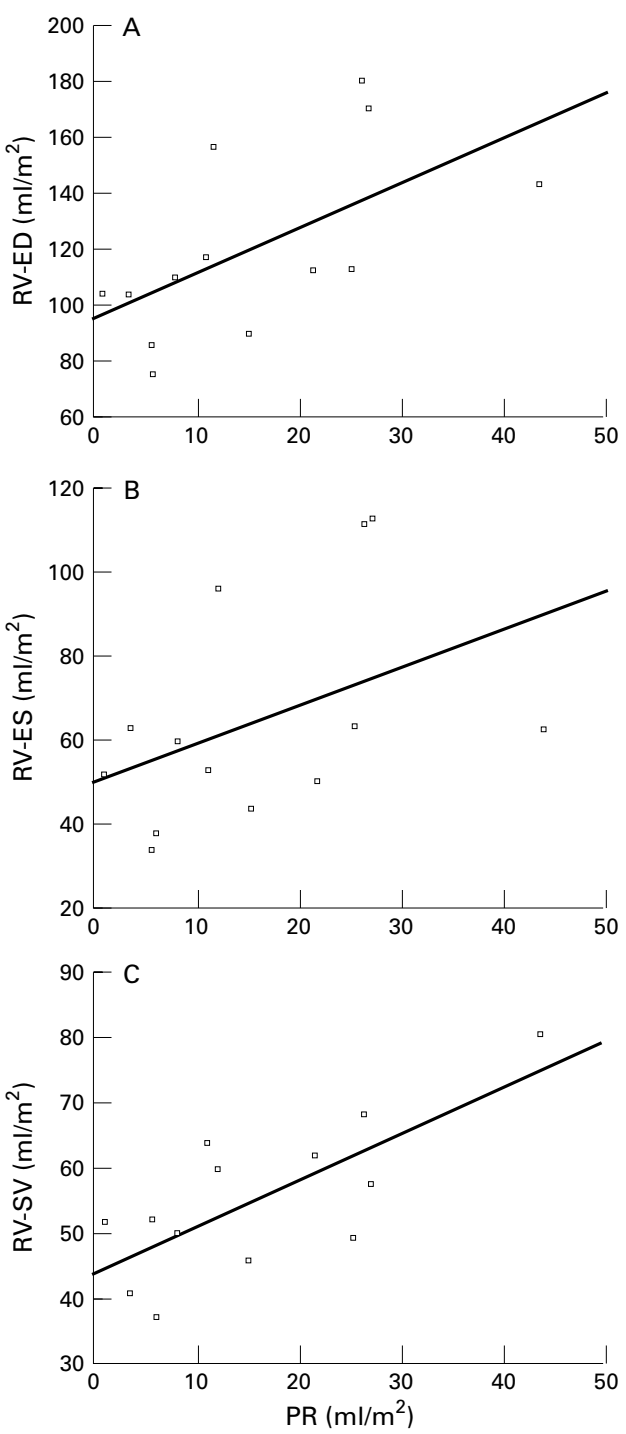

Figure 3 Regression analysis of pulmonary regurgitation $(P R)$ with right ventricular end diastolic volume (RV-ED) (A), end systolic volume (RV-ES) (B), and stroke volume $(R V-S V)(C)$ in postoperative Fallot patients.

Table 2 Comparison of mitral flow indices in patients and age matched controls

\begin{tabular}{llll}
\hline & Patients & Controls & p Value \\
\hline Time to peak E filling (ms) & $434(94)$ & $478(46)$ & NS \\
E deceleration time (ms) & $207(73)$ & $230(98)$ & NS \\
E filling fraction (\%) & $76(11)$ & $78(4)$ & NS \\
Time to peak A filling rate (ms) & $748(153)$ & $869(135)$ & NS \\
A filling fraction (\%) & $21(9)$ & $22(4)$ & NS \\
EA ratio (ml/s) & $3.1(1.7)$ & $2.4(.6)$ & NS \\
EA ratio (cm/s) & $2.5(1.1)$ & $1.9(.4)$ & NS \\
EA ratio (ml) & $4.7(2.8)$ & $3.6(.8)$ & NS \\
\hline
\end{tabular}

A, late (atrial) filling; E, early filling.

Table 3 Comparison of left ventricular indices in patients and age matched controls

\begin{tabular}{llll}
\hline & Patients & Controls & p Value \\
\hline EDV (ml/m ${ }^{2}$ ) & $78(11)$ & $88(10)$ & $<0.05$ \\
Basal ED Wth (mm) & $5.42(0.55)$ & $6.12(0.85$ & $<0.05$ \\
Midv ED Wth (mm) & $5.06(0.72)$ & $6.06(1.06)$ & $<0.05$ \\
Basal ES Wth (mm) & $7.29(0.96)$ & $8.3(1.26)$ & $<0.05$ \\
Midv ES Wth (mm) & $7.14(0.64)$ & $8.16(1.05)$ & $<0.05$ \\
Apical Wth (\%) & $68(26)$ & $48(14)$ & $<0.05$ \\
\hline
\end{tabular}

ED, end diastolic; EDV, end diastolic volume; ES, end systolic; Midv, mid-ventricular; Wth, wall thickening. respectively. Left ventricular mass in patients was lower but the difference did not reach statistical significance (51 (8) $v 56$ (9) $\mathrm{g} / \mathrm{m}^{2}, \mathrm{NS}$ ). No significant correlations were found between left ventricular volumes and the amount of pulmonary regurgitation.

\section{LEFT VENTRICULAR WALL THICKNESS}

Mean end diastolic left ventricular wall thickness of all regions was less in Fallot patients than in healthy volunteers, at $5.42(0.55) v$ $6.12(0.85) \mathrm{mm}(\mathrm{p}<0.05)$ for the basal level and $5.06(0.72) v 6.06(1.06) \mathrm{mm}(\mathrm{p}<0.05)$ for the midventricular level, respectively. At both levels, this reduced thickness was located predominantly in the left ventricular free wall regions. Mean end systolic wall thickness was less in Fallot patients than in controls, at 7.29 $(0.96) v 8.3(1.26) \mathrm{mm}(\mathrm{p}<0.05)$ for the basal level, and $7.14(0.64)$ v $8.16(1.05) \mathrm{mm}$ $(\mathrm{p}<0.05)$ for the midventricular level, respectively. At both levels, this reduced thickness was again located predominantly in the left ventricular free wall regions. End systolic wall thickness in the septal regions was reduced in the patients but the difference was not statistically significant. At the apical level, mean end systolic wall thickness did not differ significantly from that in healthy volunteers. Wall thickening in patients was not significantly different from that in controls, at 35 (14)\% v 36 (9) $\%$ (NS) for the basal level, and 43 (13)\% v $40(13) \%$ (NS) for the midventricular level. For the apical level, mean left ventricular systolic wall thickening was $20 \%$ higher in Fallot patients than in controls, at $68(26) \% v 48$ $(14) \%(p<0.05)$. For this apical level, greater wall thickening was equally distributed over the septal and free wall regions.

\section{LEFT VENTRICULAR WALL THICKENING AND}

THINNING

No significant differences were found for mean peak rate of wall thickening of all segments in Fallot patients compared with healthy volunteers, at $0.44(0.11) \% v 0.45(0.12) \%$ mean thickness/ms (NS). When peak rates of wall thickening of the eight separate wall segments were compared, no differences were found between Fallot patients and controls. No significant differences were found for mean peak rate of wall thinning of all segments in Fallot patients compared with healthy volunteers $(-0.47(0.14) \% v-0.48(0.14) \%$ mean thickness/ms (NS)). When peak rate of wall thinning of the separate wall segments were compared, no differences were found between Fallot patients and controls.

\section{LEFT VENTRICULAR ECCENTRICITY}

Fallot patients had slightly more eccentric left ventricular profiles than controls at both end systole and end diastole, but differences between the two groups were not statistically significant. At end systole, values for patients and controls were $1.15(0.11) v 1.08$ (0.07) (NS). At end diastole similar values were found (1.13 (0.12) v 1.09 (0.11) (NS)). 


\section{Discussion}

The purpose of this study was to investigate the effects of chronic pulmonary regurgitation on left ventricular function in postoperative Fallot patients with residual pulmonary regurgitation and altered right ventricular haemodynamics. The most important findings of our study were that end diastolic left ventricular volumes and overall wall thickness were reduced in Fallot patients, while global functional variables such as stroke volume, ejection fraction, and mitral flow pattern did not differ between patients and healthy subjects. In addition systolic wall thickening at the apex was $20 \%$ higher in Fallot patients. No relation was found between the amount of pulmonary regurgitation and left ventricular volumes. In addition no relation was found between right ventricular and left ventricular volumes.

As expected, our results show that in postoperative Fallot patients with residual pulmonary regurgitation, right ventricular volumes are larger than in controls. The close relation between the severity of pulmonary regurgitation and the degree of right ventricular enlargement reflects the effect of the chronic volume load on the right ventricle and is in agreement with earlier studies. ${ }^{2514}$

Assessment of left ventricular function in postoperative Fallot patients in various studies has produced divergent results. Reduto et al reported normal left ventricular performance and normal exercise reserve in a radionuclide study of adolescent and adult Fallot patients with mild pulmonary regurgitation. ${ }^{6}$ Borow et al found left ventricular dysfunction unmasked by an afterload stress in the older Fallot patients but not in the patients repaired during infancy. ${ }^{7}$ Bove et al found a decreased left ventricular ejection fraction using radionuclide ventriculography in 12 adolescent patients with moderate to severe pulmonary regurgitation. ${ }^{2}$ Waien et al studied 36 adult patients with repaired tetralogy of Fallot for a mean period of 6.7 years after the operation using exercise radionuclide angiography. ${ }^{8}$ They found left ventricular ejection fractions decreased with time but remained within normal limits. They therefore concluded that ventricular function may deteriorate over time and should be carefully monitored. Kavey et al found a normal left ventricular ejection fraction in young patients after Fallot repair studied with cine $x$ ray angiography. ${ }^{11}$ In another study by the same group using radionuclide ventriculography, depressed left ventricular ejection fraction was found only in postoperative Fallot patients with documented ventricular arrhythmias, not in those without rhythm disturbances. ${ }^{9}$ In 63 patients after complete repair of tetralogy of Fallot studied using angiocardiography, Oku et al found impaired left ventricular function only in those with a high grade pulmonary regurgitation. ${ }^{10}$ Marie et al studied 35 postoperative Fallot patients using cardiac catheterisation, echocardiography, and radionuclide angiography and found normal or near normal left ventricular dimensions and ejection fraction in all patients, including those with residual right ventricular pressure overload. ${ }^{12}$ Possible reasons for these contradic- tory findings may be differences in the amount of residual pulmonary stenosis or regurgitation between patient groups. In addition, the age of the studied patients and postoperative time period were not comparable in all previously mentioned studies. Two important limitations of the diagnostic tools used in previous studies (echocardiography, $x$ ray angiography, and radionuclide ventriculography) are the inability to measure the exact amount of pulmonary regurgitation and difficulties in the assessment of ventricular volumetrics, particularly of the right ventricle. However, in Fallot patients, assessment of the left ventricle may also pose a problem, as the shape of the left ventricle is often altered owing to right ventricular volume or pressure overload. Thus an ellipsoid shape of the left ventricle cannot be assumed. ${ }^{21}$ We have previously reported the accuracy of MRI flow measurements in the determination of the amount of pulmonary regurgitation in Fallot patients. ${ }^{514}$ In addition, MRI allows the assessment of ventricular volumes and global function without the use of geometric assumptions. ${ }^{22}$

In the present study we found a decreased left ventricular end diastolic volume with normal left ventricular ejection fraction. This is in accordance with previous reports of relatively older patient groups with right ventricular volume overload. ${ }^{23}{ }^{24}$ The myocardial contractile function of the left ventricle in right ventricular volume overload lesions has been shown to be normal. ${ }^{25}$ Matched for differences in end diastolic volume, left ventricular ejection fraction is decreased in right ventricular volume overload compared with normal hearts. ${ }^{26}$ Furthermore, the contribution of the left atrium to left ventricular filling has been shown to be reduced in right ventricular volume overload states. ${ }^{26-28}$ These factors have been explained by the shift of the position of the interventricular septum, particularly in diastole, ${ }^{26}{ }^{29}$ resulting in a net motion of the septum towards the left ventricle. It is not known how much right ventricular volume overload there should be for these changes in left ventricular function to occur. Our study shows a slight reduction in left ventricular end diastolic volume, a non-significant change in left ventricular shape, normal left ventricular ejection fraction, and normal indices of left ventricular diastolic function. Therefore we conclude that mild pulmonary regurgitation (25 (18)\% of right ventricular output) is insufficient to impair left ventricular function. Of note, in an earlier study of 19 young Fallot patients with moderate to severe pulmonary regurgitation (39 (16)\% of right ventricular output), we found that left ventricular end diastolic volume was normal and left ventricular ejection fraction was significantly lower in patients. ${ }^{14}$ A possible explanation for a normal left ventricular ejection fraction in the present study, as opposed to a diminished left ventricular ejection fraction in a previous study performed in children, ${ }^{14}$ may be the lesser degree of pulmonary regurgitation in the adult patient group.

Although left ventricular wall thickness values were within normal limits for patients as 
well as healthy subjects, a statistically significant difference was found between the two groups. Overall wall thickness was reduced in Fallot patients and this reduction was located predominantly in the left ventricular free wall regions. This reduced wall thickness may represent global injury to the myocardium sustained during surgery or preoperative cyanosis, or it may reflect diminished global physical activity of these patients in daily life. ${ }^{9}{ }^{30}$ Further study of left ventricular function in patients operated on in infancy would be helpful to determine possible beneficial effects of early surgery on left ventricular wall thickness. We can only speculate on the origin of this reduced wall thickness and suggest that further study is needed to clarify this finding.

Although the septum is by convention considered to be part of the left ventricle, it is also part of the right ventricle and thus the relatively normal values of septal wall thickness observed in our study may be the result of persisting right ventricular hypertrophy, a common finding in tetralogy of Fallot. ${ }^{14}{ }^{31}$ Wall thickening at basal and midventricular levels was not different in patients, suggesting normal contractility at these levels. For the apical level, left ventricular systolic wall thickening was $20 \%$ greater in Fallot patients and equally distributed over the wall regions. Hypercontractility of the apical level was also reported by Nakasato et al studying postoperative Fallot patients using $x$ ray ventriculography. ${ }^{32}$ In the absence of significant left ventricular eccentricity, this phenomenon has so far not been explained. Hypercontractility of the apex may constitute a form of remodelling of the left ventricle in these patients which may lead to preservation of global function (that is, stroke volume and ejection fraction), despite lower overall wall thickness.

CLINICAL IMPLICATIONS

Our findings in the present study indicate that in adult Fallot patients with a residual pulmonary regurgitation of 25 (18)\% of right ventricular output, no significant effect on the shape and function of the left ventricle is to be expected. However, considering previous reports of a potential deterioration of left ventricular function with time, serial evaluation of left ventricular function is required in tetralogy of Fallot. ${ }^{33}$ The same is true for right ventricular function. ${ }^{13}$ Little is known of the development of the percentage of pulmonary regurgitation in relation to the time elapsed after operation in these patients, and how this will influence biventricular function. Therefore, clinical management of these patients should include quantification of pulmonary regurgitation and of biventricular volumes and function, which may provide early detection of impaired ventricular function and may assist in the timing of possible reinterventions. MRI can play an important role in this setting by providing a tool for accurate quantification of the degree of pulmonary regurgitation and assessment of biventricular function. ${ }^{513-15}$
LIMITATIONS

Not all patients were operated on using the same surgical technique. In addition, our patient group consisted only of adults; therefore the effects of the currently preferred early surgery on left ventricular function could not be evaluated. Moreover, as assessment of left ventricular function under stress may reveal a diminished reserve of cardiac function, it would be desirable to perform MRI studies in these patients during exercise. ${ }^{635}$

\section{CONCLUSIONS}

Adult patients 24 (8) years after Fallot surgery, with chronic residual pulmonary regurgitation of $25(18) \%$ of right ventricular output, have normal left ventricular shape and global function. Overall left ventricular wall thickness was decreased, possibly reflecting subtle global myocardial injury. Hypercontractility of the apex may lead to preservation of global function.

Financial support to RAN was provided by The Interuniversity Cardiology Institute of The Netherlands (ICIN), Utrecht, Netherlands.

1 Murphy JG, Gersh BJ, Mair DD, et al. Long-term outcome cal repair of tetralogy of Fallot. N Engl f Med 1993;329:593-9.

2 Bove EL, Byrum CJ, Thomas FD, et al. The influence of pulmonary insufficiency on ventricular function following repair of tetralogy of Fallot. Evaluation using radionuclide

ventriculography. F Thorac Cardiovasc Surg 1983;85:691-6. Zahka KG, Horneffer PJ, Rowe SA, et al. Long-term valvu-
lar function after total repair of tetralogy of Fallot. Circulalar function after total repair of

Rosenthal A. Adults with tetralogy of Fallot-repaired, yes; cured, no [editorial]. N Engl f Med 1993;329:655-6.

5 Rebergen SA, Chin JGJ, Ottenkamp J, et al. Pulmonary regurgitation in the late postoperative follow-up of tetralogy of Fallot: volumetric quantitation by nuclear magnetic resonance velocity mapping. Circulation 1993; 88(part 1):2257-66

6 Reduto LA, Berger HJ, Johnstone DE, et al. Radionuclide assessment of right and left ventricular exercise reserve after total correction of tetralogy of Fallot. Am f Cardiol 1980;45:1013-18.

7 Borow KM, Green LH, Castaneda AR, et al. Left ventricular function after repair of tetralogy of Fallot and its
relationship to age at surgery. Circulation 1980;61:1150-8.

8 Waien SA, Liu PP, Ross BL, et al. Serial follow-up of adults with repaired tetralogy of Fallot. $\mathcal{F} \mathrm{Am}$ Coll Cardiol with repaired tetral.

9 Kavey RE, Thomas FD, Byrum CJ, et al. Ventricular arrhythmias and biventricular dysfunction after repair of tetralogy of Fallot. 7 Am Coll Cardiol 1984;4:126-31.

$10 \mathrm{Oku} \mathrm{H}$, Shirontani H, Sunakawa A, et al. Postoperative long-term results in total correction of tetralogy of Fallot: hemodynamics and cardiac function. Ann Thorac Surg 1986;41:413-18

11 Kavey RE, Bove EL, Byrum CJ, et al. Postoperative functional assessment of a modified surgical approach to repair of tetralogy of Fallot. 7 Thorac Cardiovasc Surg 1987; 93:533-8

12 Marie PY, Marcon F, Brunotte F, et al. Right ventricular overload and induced sustained ventricular tachycardia in operatively "repaired" tetralogy of Fallot. Am \& Cardiol 1992;69:785-9.

13 Helbing WA, Niezen RA, Le Cessie S, et al. Right ventricular diastolic function in children with pulmonary regurgitation after repair of tetralogy of Fallot: volumetric evaluation by magnetic resonance velocity mapping. $7 \mathrm{Am}$ Coll Cardiol by magnetic reson

14 Niezen RA, Helbing WA, van der Wall EE, et al. Biventricular systolic function and mass studied with MR imaging in children with pulmonary regurgitation after repair for tetralogy of Fallot. Radiology 1996;201:135-40

15 Chaturvedi RR, Kilner PJ, White PA, et al. Increased airway pressure and simulated branch pulmonary artery stenosis increase pulmonary regurgitation after repair of tetralogy of Fallot. Real-time analysis with a conductance catheter technique. Circulation 1997;95:643-9.

16 van der Geest RJ, Buller VG, Jansen E, et al. Comparison between manual and semiautomated analysis of left ventricular volume parameters from short-axis MR images. f Comput Assist Tomogr 1997;21:756-65.

17 Van der Geest RJ, Niezen R, Buller VGM, et al. Automated quantification of flow velocity and volume in the ascending and descending aorta using MR flow velocity. $\mathcal{F}$ Comput Assist Tomogr 1998;22:904-11. 
18 Buller VGM, van der Geest RJ, Kool MD, et al. Assessment of regional left ventricular wall parameters from short axis magnetic resonance imaging using a three dimensiona extension to the improved centerline method. Invest Radio 1997;32:529-39.

19 Lamb HJ, Singleton RR, van der Geest RJ, et al. MR imag ing of regional cardiac function: low-pass filtering of wall thickness curves. Magn Reson Med 1995;343:498-502.

20 Dendale PA, Franken PR, Waldman GJ, et al. Regiona diastolic wall motion dynamics in anterior myocardial infarction: analysis and quantification with magnetic resonance imaging. Coron Artery Dis 1995;6:723-9.

21 Ryan T, Petrovic O, Dillon JC, et al. An echocardiographic index for separation of right ventricular volume and pressure overload. F Am Coll Cardiol 1985;5:918-27.

22 Lotan CS, Cranney GB, Bouchard A, et al. The value of cine nuclear magnetic resonance imaging for assessing regional .

23 Graham TJ, Jarmakani JM, Canent RJ. Left heart volume characteristics with a right ventricular volume overload. Total anomalous pulmonary venous connection and large Total anomalous pulmonary venous connection

24 Benson LN, Child JS, Schwaiger M, et al. Left ventricular geometry and function in adults with Ebstein's anomaly of the tricuspid valve. Circulation 1987;75:353-9.

25 Urabe Y, Hamada Y, Spinale FG, et al. Cardiocyte contractile performance in experimental biventricular volumeoverload hypertrophy. Am f Physiol 1993;264:H1615-23.

26 Lin SS, Reynertson SI, Louie EK, et al. Right ventricular volume overload results in depression of left ventricular ejection fraction. Implications for the surgical management of tricuspid valve disease. Circulation 1994;90:I209-13.
27 Louie EK, Bieniarz T, Moore AM, et al. Reduced atrial contribution to left ventricular filling in patients with severe tricuspid regurgitation after tricuspid valvulectomy: a Doppler echocardiographic study. F Am Coll Cardiol 1990;16: $1617-24$

28 Louie EK, Rich S, Levitsky S, et al. Doppler echocardiographic demonstration of the differential effects of right ventricular pressure and volume overload on left ventricular geometry and filling. F Am Coll Cardiol 1992;19:84-90.

29 Ascah KJ, King ME, Gillam LD, et al. The effects of right ventricular hemodynamics on left ventricular configuration. Can f Cardiol 1990;6:99-106.

30 Lorgeril de M, Friedli B, Assimacopoulos A. Factors affecting left ventricular function after correction of tetralogy of Fallot. Br Heart 7 1984;52:536-41.

31 Mitsuno M, Nakano S, Shimazaki Y, et al. Fate of right ventricular hypertrophy in tetralogy of Fallot after corrective tricular hypertrophy in tetralogy of $\mathrm{F}$
surgery. Am $\mathrm{f}$ Cardiol 1993;72:694-8.

32 Nakasato M, Akiba T, Sato $S$, et al. Right and left ventricular function assessed by regional wall motion analysis in patients with tetralogy of Fallot. Int 7 Cardiol 1997;58:127patient

33 Misbach GA, Turley K, Ebert PA. Pulmonary valve replacement for regurgitation after repair of tetralogy of Fallot. Ann Thorac Surg 1983;36:684-91.

34 Ilbawi MN, Idriss FS, DeLeon SY, et al. Long-term results of porcine valve insertion for pulmonary regurgitation following repair of tetralogy of Fallot. Ann Thorac Surg 1986; 41:478-82.

35 Kondo C, Nakazawa M, Kusakabe K, et al. Left ventricular dysfunction on exercise long-term after total repair of tetralogy of Fallot. Circulation 1995;92(suppl 9):I250-5. 